\title{
Salivary Gland Neoplasm
}

National Cancer Institute

\section{Source}

National Cancer Institute. Salivary Gland Neoplasm. NCI Thesaurus. Code C3361.

A benign or malignant neoplasm that affects the major or minor salivary glands.

Representative examples of benign neoplasms include Warthin tumor, monomorphic adenoma, and pleomorphic adenoma. Representative examples of malignant neoplasms include carcinoma, lymphoma, and sarcoma. 